\title{
Crescimento de eucalipto em diferentes arranjos espaciais de sistemas silvipastoris no município de Santa Rita do Trivelato - Mato Grosso
}

\author{
Hudson Santos Souza $\bullet^{1 *}$ Alessandra da Silva Lopes $\oplus^{2}$ Maisa Caroline Baretta $\oplus^{3}$ Joilson \\ Onofre Pereira dos Santos $\mathbb{1}^{4}$ Antonio de Arruda Tsukamoto Filho $\oplus^{5}$
}

${ }^{1}$ Engenheiro Florestal, MSc. em Ciências Florestais e Ambientais, UFMT, Cuiabá, MT, Brasil

${ }^{2}$ Eng. Florestal, MSc. Ciências Florestais e Ambientais/UFMT, doutoranda Universidade Estadual Paulista Júlio de Mesquita Filho, SP, Brasil ${ }^{3}$ Engenheira Florestal, MSc. em Ciências Florestais e Ambientais, UFMT, Cuiabá, MT, Brasil

${ }^{4}$ Engenheiro Florestal, MSc. em Ciências Florestais e Ambientais, UFMT, Cuiabá, MT, Brasil

${ }^{5}$ Universidade Federal do Mato Grosso, Av. Fernando Corrêa da Costa, 2367, Boa Esperança, CEP 78060-900, Cuiabá, MT, Brasil

\begin{abstract}
Original Article
*Corresponding author: hudsonssh7@gmail.com

Palavras-chave:

Sistemas agroflorestais

Sustentabilidade

Espécies exóticas

Keywords:

Agroforestry

Sustainability

RESUMO: O objetivo do trabalho foi avaliar o crescimento de eucalipto em diferentes arranjos espaciais de sistemas silvipastoris no município de Santa Rita do Trivelato - MT. Foram avaliados três arranjos espaciais com materiais genéticos formados por dois clones de híbridos e um material seminal em três arranjos espaciais. No arranjo 1 (A1) foi utilizado o clone H13 implantado em linhas simples em espaçamento de $10 \times 3 \mathrm{~m}$; o arranjo 2 (A2) foi composto pelo plantio de um material seminal em espaçamento de $10 \times 2,5 \mathrm{~m}$ e o arranjo 3 (A3) pelo clone I042 no espaçamento 3x4x16 m. Em A1 e A3 não houve diferença significativa de sobrevivência até o sexto ano de idade. A partir do terceiro até o sexto ano, A2 obteve a menor sobrevivência chegando a $62,4 \%$ no sexto ano. A3 apresentou as maiores médias em dap $(20,72 \mathrm{~cm})$, altura total $(20,61 \mathrm{~m})$ e volume total por indivíduo $\left(0,2769 \mathrm{~m}^{3}\right)$. No sexto ano após o plantio do eucalipto, A3 apresentou incremento médio anual (ima) de 15,8 $\mathrm{m}^{3} \mathrm{ha}^{-1} \mathrm{ano}^{-1}$, A1 ima de 10,1 $\mathrm{m}^{3}$ ha $^{-1}$ ano $^{-1}$ e A2 ima de $6,7 \mathrm{~m}^{3} \mathrm{ha}^{-1}$ ano $^{-1}$.
\end{abstract}

Exotic species

Received in

2017/08/21

Accepted on

2020/03/02

Published in

2020/04/03

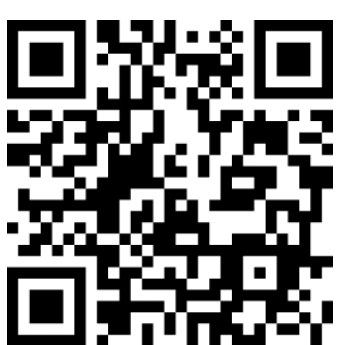

DOI:

http://dx.doi.org/10.34062/af s.v7i1.5511

\section{(cc) BY}

\section{Growth of eucalyptus in different spatial arrangements of silvipastoral systems in the municipality of Santa Rita do Trivelato - Mato Grosso}

\begin{abstract}
The objective of this work was to evaluate the growth of eucalyptus in different spatial arrangements of silvipastoral systems in the municipality of Santa Rita do Trivelato - MT. Three spatial arrays with genetic materials consisting of two hybrid clones and one seminal in three spatial arrays were evaluated. In arrangement 1 (A1) was used the clone H13 implanted in simple lines in 10x3 m spacing; Arrangement 2 (A2) was composed by planting a seminal material in $10 \times 2.5 \mathrm{~m}$ spacing and arrangement 3 (A3) by clone I042 in $3 \times 4 \times 16 \mathrm{~m}$ spacing. In A1 and A3 there was no significant difference in survival until the sixth year of age. From the third through the sixth year, A2 had the lowest survival reaching $62.4 \%$ in the sixth year. A3 presented the best averages in dap (20.72 $\mathrm{cm})$, total height $(20.61 \mathrm{~m})$ and individual total volume $\left(0.2769 \mathrm{~m}^{3}\right)$. In the sixth year after eucalyptus planting, A3 had an average annual increment of $15.8 \mathrm{~m}^{3} \mathrm{ha}^{-}$ ${ }^{1}$ year $^{-1}$, A1 an average annual increment of $10.1 \mathrm{~m}^{3} \mathrm{ha}^{-1}$ year-1 and A2 an average annual increment of $6.7 \mathrm{~m}^{3} \mathrm{ha}^{-1}$ year $^{-1}$.
\end{abstract}




\section{Introdução}

No Brasil, a área de floresta plantada atingiu 7,83 milhões de hectares em 2018, sendo que os plantios de eucalipto ocupam 5,7 milhões de hectares (IBÁ, 2019). De acordo com Monte et al. (2009) a crescente utilização da madeira de eucalipto deve-se às suas características físico-mecânicas e estéticas diferenciadas, destacando a possibilidade de uso para produção de móveis.

Esses números demonstram que o eucalipto é uma espécie muito importante no Brasil e seu papel de destaque torna-se primordial pelo fato da espécie também apresentar grande potencial de utilização em sistemas silvipastoris, devido ao seu crescimento rápido, forma de copa adequada e pouco densa, além dos múltiplos usos da madeira.

Segundo Andrade et al. (2012), os sistemas silvipastoris consistem em sistemas produtivos que integram árvores e pastagens destinadas à criação de animais na mesma área, visando conferir maior sustentabilidade ao sistema, por meio das interações ecológicas e econômicas positivas entre os componentes.

De acordo com Aquino e Assis (2005), a introdução de árvores e arbustos, em pastagens de gramíneas, pode acarretar vários benefícios, em alguns casos ocorrendo externalidades positivas que ultrapassam os limites da pastagem ou da propriedade. Entre esses efeitos, destacam-se: conforto para os animais, controle de erosão e melhoramento da fertilidade do solo, melhor aproveitamento da água das chuvas, aumento na disponibilidade de forragem em certas épocas do ano e maiores teores de proteína bruta na forragem sombreada, incremento da rentabilidade da propriedade rural, com redução nos gastos com insumos e, algumas vezes, com a obtenção de pelo menos dois produtos comercializáveis (leite, carne, madeira, frutas, etc.), aumento e conservação da biodiversidade e proteção dos mananciais de água.

$\mathrm{O}$ uso do eucalipto em sistemas silvipastoris no Brasil foi objeto de estudo de vários pesquisadores, tais como Porfírio-da-Silva (2012), Cruz (2007), Andrade (2000), Toledo et al. (1999) e Couto et al. (1994). Todavia, no Estado de Mato Grosso são poucas as experiências nesse sentido, tornando essenciais as pesquisas que demonstrem o comportamento silvicultural do eucalipto nos sistemas silvipastoris em diferentes arranjos espaciais.

Nesse aspecto, o objetivo deste estudo foi avaliar o crescimento do eucalipto no sistema silvipastoril, em diferentes arranjos espaciais, considerando material clonal e seminal, no município de Santa Rita do Trivelato - MT.

\section{Material e Métodos}

O estudo foi desenvolvido na fazenda BeijaFlor 4, circunscrita sob às coordenadas $13^{\circ} 58^{\prime} 34.56^{\prime \prime} \mathrm{S}$ e $55^{\circ} 01^{\prime} 00.50 " \mathrm{~W}$, no município de
Santa Rita do Trivelato - MT. O clima da região é do tipo Aw com estação seca, segundo a classificação de Köppen, com temperatura média anual variando de 24 a $26^{\circ} \mathrm{C}$ e precipitação média anual de 1600 a $1900 \mathrm{~mm}$ (Alvares et al., 2013).

As análises foram realizadas em três diferentes áreas da fazenda, denominadas de arranjo espacial 1 (A1) (talhões 1, 3 e 6), arranjo espacial 2 (A2) (talhão 7) e arranjo espacial 3 (A3) (talhão 8).

Em A1, o material genético do eucalipto foi o clone H13 (Eucalyptus urophyla x Eucalyptus grandis), plantado no espaçamento $10 \times 3 \mathrm{~m}$. A área total plantada foi de 342,06 ha com uma densidade de 333 plantas por hectare. Em A2, o material genético do eucalipto foi seminal (Eucalyptus urophyla $\mathrm{x}$ Eucalyptus grandis), plantado no espaçamento $10 \times 2,5 \mathrm{~m}$. A área total foi de 176,18 ha com uma densidade de 400 plantas por hectare. Em A3 o material genético do eucalipto foi o clone IO42 (Eucalyptus urophyla x Eucalyptus grandis), plantado no espaçamento $3 \times 4 \times 16 \mathrm{~m}$. A área total plantada foi 709,45 ha e a densidade do plantio foi de 333 plantas por hectare.

Em comum nas três áreas, antes do plantio das mudas, foi a realização de uma gradagem pesada e uma niveladora, seguida de calagem com aplicação de 2 ton ha ${ }^{-1}$ de calcário dolomítico. Antes de serem plantadas, as mudas de eucalipto foram imergidas em uma solução à base de fipronil. Ao terceiro mês foi feito o coroamento das mudas em um raio de 1 $\mathrm{m}$. O controle de formigas foi feito com sulfluramida antes do plantio e a cada seis meses, utilizando em média 1,5 kg ha-1 em cada aplicação. A brachiaria (Urochloa brizantha cv. Marandu) foi plantada com auxílio de um distribuidor de $3 \mathrm{~m}$ de largura e rolo compactador, aplicando-se $12 \mathrm{~kg}$ de sementes ha- ${ }^{-1}$.

Após 18 meses de implantado o eucalipto, foi inserido o gado da raça Nelore. A desrama do eucalipto foi realizada no $2^{\circ}$ ano até $2 \mathrm{~m}$ de altura, no $3^{\circ}$ ano até $4 \mathrm{~m}$ e no $4^{\circ}$ ano até $7 \mathrm{~m}$. O critério utilizado para a desrama foi o diâmetro mínimo de $8-10 \mathrm{~cm}$ e/ou altura compatível do ponto de vista ergonômico. Ainda não foi realizado desbaste nas áreas.

Para avaliar o crescimento das árvores de eucalipto nas três áreas foi realizada a medição da altura total (ht) de 10 árvores aleatórias da parcela e do diâmetro a 1,30 $\mathrm{m}$ da superfície do solo (dap) de todas as 30 árvores da parcela, do $1^{\circ}$ ao $6^{\circ}$ ano de idade. Cada área continha seis parcelas permanentes de $900 \mathrm{~m}^{2}$ (30x30 m).

Para a estimativa da altura total das demais árvores que não foram coletadas as alturas, foram ajustadas as equações 1, 2 e 3 (Barros et al., 2002), que levam em consideração a variável idade (I) para cada área.

Devido ainda não ter realizado a cubagem das árvores, foi aplicado a equação 4 em cada área para a estimativa do volume. Essa equação foi ajustada por Ferreira et al. (2014) para clones de Eucalyptus 
urophylla $\mathrm{x}$ Eucalyptus grandis aos seis anos de idade, onde o autor obteve um $\mathrm{R}^{2}$ ajustado de $0,98 \mathrm{e}$ Syx de $8,9 \%$. Foi avaliada a sobrevivência (S\%), a tendência do crescimento em diâmetro a $1,30 \mathrm{~m}$ do solo (dap), altura total (ht) e volume total (vt) para cada área, com a aplicação do teste t para amostras independentes, ao nível de 5\% de significância, para verificar diferenças significativas entre as áreas do $1^{\circ}$ ao $6^{\circ}$ ano de idade.

$\mathrm{Na}$ estimativa da produção em volume foi ajustado o modelo de Gompertz (Campos e Leite, 2013) (Eq. 5, 6 e 7) para cada uma das áreas e posteriormente foram avaliados o incremento médio anual (ima) e o incremento corrente anual (ica) em volume.

$$
\begin{aligned}
& \ln h t=3,739-8,966\left(\frac{1}{\text { dap }}\right)-1,536\left(\frac{1}{I}\right)+7,146\left(\frac{1}{\text { dap }} I\right)\left(\mathrm{R}^{2}=0,922\right. \text { Syx\%=12,23) } \\
& \ln h t=3,582-7,526\left(\frac{1}{\text { dap }}\right)-1,299\left(\frac{1}{I}\right)+5,174\left(\frac{1}{\text { dap }} I\right)\left(\mathrm{R}^{2}=0,886 \text { Syx } \%=10,94\right) \\
& \ln h t=3,951-10,342\left(\frac{1}{\text { dap }}\right)-1,536\left(\frac{1}{I}\right)+7,146\left(\frac{1}{\text { dap }} I\right)\left(\mathrm{R}^{2}=0,923 \text { Syx } \%=12,51\right)
\end{aligned}
$$

Em que: $h t=$ altura total $(\mathrm{m}) ;$ dap = diâmetro a $1,30 \mathrm{~m}$ da superfície do solo $(\mathrm{cm}) ; I=$ idade $($ anos $) ; \ln =$ logaritmo neperiano; $\mathrm{R}^{2}=$ coeficiente de determinação; Syx \% = erro padrão residual em porcentagem.

$$
v t=\exp ^{\left(-12,631-\left(0,132 *\left(\frac{d a p^{2}}{h t}\right)\right)+4,295 * \ln (\text { dap })+0,215 * \ln (h t)\right.}
$$

Em que: $v t=$ volume total $\left(\mathrm{m}^{3}\right) ; \exp =$ expoente; dap = diâmetro a $1,30 \mathrm{~m}$ da superfície do solo $(\mathrm{cm}) ; h t=$ altura total $(\mathrm{m}) ; \mathrm{ln}=$ logaritmo neperiano.

$$
\begin{array}{ll}
Y=72,587 \exp ^{-\exp ^{1,682-0,570 I}} & \left(\mathrm{R}^{2}=0,930 \text { Syx } \%=17,47\right) \\
Y=44,361 \exp ^{-\exp ^{1,410-0,630 I}} & \left(\mathrm{R}^{2}=0,931 \text { Syx } \%=14,24\right) \\
Y=107,025 \exp ^{-\exp ^{1,953-0,685 I}} & \left(\mathrm{R}^{2}=0,987 \text { Syx} \%=7,69\right)
\end{array}
$$

Em que: $Y=$ produção em $\mathrm{m}^{3}$ por hectare; $\exp =$ expoente; $I=$ idade em anos.

\section{Resultados}

A Tabela 1 contém a sobrevivência do eucalipto das três áreas avaliadas. No primeiro ano não houve diferença significativa na sobrevivência entre os arranjos, porém no sexto ano A2 diferiu das demais.
A Tabela 2 contém as estatísticas descritivas das variáveis dap, altura total e volume total do

\begin{tabular}{|c|c|c|c|c|c|c|}
\hline \multicolumn{2}{|c|}{ Estatística } & Min & $\bar{x}$ & Máx & $\mathrm{s}$ & $\mathrm{CV} \%$ \\
\hline \multirow{3}{*}{ A1 } & $\operatorname{dap}(\mathrm{cm})$ & 4,14 & 20,49 & 29,44 & 4,01 & 19,56 \\
\hline & $h t(\mathrm{~m})$ & 4,98 & 22,33 & 29,50 & 2,93 & 13,11 \\
\hline & $v t\left(\mathrm{~m}^{3}\right)$ & 0,0013 & 0,2165 & 0,4525 & 0,0671 & 31,01 \\
\hline \multirow{3}{*}{ A2 } & $\operatorname{dap}(\mathrm{cm})$ & 8,28 & 19,94 & 32,47 & 4,75 & 23,83 \\
\hline & $h t(\mathrm{~m})$ & 13,46 & 20,60 & 29,90 & 2,32 & 11,25 \\
\hline & $v t\left(\mathrm{~m}^{3}\right)$ & 0,0256 & 0,1635 & 0,3391 & 0,0482 & 29,69 \\
\hline \multirow{3}{*}{ A3 } & $d a p(\mathrm{~cm})$ & 6,37 & 20,72 & 32,48 & 4,70 & 22,67 \\
\hline & $h t(\mathrm{~m})$ & 11,00 & 24,61 & 30,24 & 3,61 & 13,94 \\
\hline & $v t\left(\mathrm{~m}^{3}\right)$ & 0,0095 & 0,2769 & 0,4268 & 0,1044 & 33,25 \\
\hline
\end{tabular}
eucalipto aos seis anos de idade.

Na Tabela 3 estão as comparações das variáveis avaliadas nos três arranjos.

Tabela 1. Sobrevivência do eucalipto em sistema silvipastoril no município de Santa Rita do Trivelato - MT.

\begin{tabular}{ccccccc}
\hline Arranjo & \multicolumn{5}{c}{ Sobrevivência $(\%)$} \\
espacial & $1^{\circ}$ ano & $2^{\circ}$ ano & $3^{\circ}$ ano & $4^{\circ}$ ano & $5^{\circ}$ ano & $6^{\circ}$ ano \\
\hline A1 x A2 & 93,3 e $90,0^{\text {ns }}$ & 93,2 e $89,5^{\text {ns }}$ & 93,0 e $72,9^{*}$ & 92,2 e $69,5^{*}$ & 92,2 e $65,2^{*}$ & 91,8 e $62,4^{*}$ \\
A1 x A3 & 93,3 e $94,4^{\text {ns }}$ & 93,2 e $93,9^{\text {ns }}$ & 93,0 e $93,3^{\text {ns }}$ & 92,2 e $93,3^{\text {ns }}$ & 92,2 e $92,8^{\text {ns }}$ & 91,8 e $92,2^{\text {ns }}$ \\
A2 x A3 & 90,0 e $94,4^{\text {ns }}$ & 89,5 e $93,9^{\text {ns }}$ & 72,9 e $93,3^{*}$ & 69,5 e $93,3^{*}$ & 65,2 e $92,8^{*}$ & 62,4 e $92,2^{*}$ \\
\hline
\end{tabular}

$*$ = significativo a $5 \% ;{ }^{\mathrm{ns}}=$ não significativo a $5 \%$ de probabilidade pelo teste $\mathrm{t}$ para amostras independentes.

Tabela 2. Estatísticas descritivas para as variáveis dendrométricas ao $6^{\circ}$ ano de idade, para os três arranjos espaciais de plantio.

$\overline{\bar{x}}=$ média aritmética; $\mathrm{s}=$ desvio padrão; $\mathrm{CV} \%$ = coeficiente de variação em porcentagem; Min = valor mínimo; Máx = valor máximo; $d a p=$ diâmetro à altura de $1,30 \mathrm{~m}$ do solo; $h t=$ altura total; $v t=$ volume total com casca . 
Souza et al.

Tabela 3. Comparação dos valores médios de diâmetro a 1,30 m do solo (dap), altura total (ht) e volume (vt) por idade, para cada combinação das áreas, utilizando teste t para amostras independentes.

\begin{tabular}{|c|c|c|c|}
\hline \multirow{2}{*}{ Idade (anos) } & \multicolumn{3}{|c|}{ Combinação dos arranjos espaciais } \\
\hline & A1 e A2 & A1 e A3 & $\mathrm{A} 2$ e $\mathrm{A} 3$ \\
\hline & \multicolumn{3}{|c|}{ dap $(\mathrm{cm})$} \\
\hline 1 & 7,53 e $7,28^{\mathrm{ns}}$ & 7,53 e $6,04^{*}$ & 7,28 e $6,04^{*}$ \\
\hline 2 & 11,99 e $10,86^{*}$ & 11,99 e $11,30^{*}$ & 10,86 e $11,30^{\text {ns }}$ \\
\hline 3 & 12,92 e $10,86^{*}$ & 12,92 e $11,30^{*}$ & 10,86 e $11,30^{\text {ns }}$ \\
\hline 4 & 17,10 e $16,38^{*}$ & 17,10 e $17,19^{\text {ns }}$ & 16,38 e $17,19^{\text {ns }}$ \\
\hline 5 & 18,71 e $17,92^{*}$ & 20,63 e $22,69^{*}$ & 17,92 e $18,70^{\text {ns }}$ \\
\hline \multirow[t]{2}{*}{6} & 20,49 e $19,94^{\mathrm{ns}}$ & 20,49 e $20,72^{\text {ns }}$ & 19,94 e $20,72^{\text {ns }}$ \\
\hline & \multicolumn{3}{|c|}{ Altura total (m) } \\
\hline 1 & 7,02 e $6,97^{\mathrm{ns}}$ & 7,02 e $6,37^{*}$ & 6,97 e $6,37^{*}$ \\
\hline 2 & 12,30 e $11,85^{*}$ & 12,30 e $11,93^{*}$ & 11,85 e $11,93^{\text {ns }}$ \\
\hline 3 & 14,27 e $12,99^{*}$ & 14,27 e $13,45^{*}$ & 12,99 e $13,45^{\text {ns }}$ \\
\hline 4 & 18,36 e $14,41^{*}$ & 18,36 e $20,77^{*}$ & 17,41 e $20,77^{*}$ \\
\hline 5 & 20,63 e $19,09^{*}$ & 20,63 e $22,69^{*}$ & 19,09 e $22,69^{*}$ \\
\hline \multirow[t]{2}{*}{6} & 22,33 e $20,60^{*}$ & 22,33 e $24,61^{*}$ & 20,60 e $24,61^{*}$ \\
\hline & \multicolumn{3}{|c|}{ Volume total $\left(\mathrm{m}^{3}\right)$} \\
\hline 1 & 0,0110 e $0,0100^{*}$ & 0,0110 e $0,0064^{*}$ & 0,0100 e $0,0064^{*}$ \\
\hline 2 & 0,0536 e $0,0440^{*}$ & 0,0536 e $0,0485^{*}$ & 0,0440 e $0,0485^{*}$ \\
\hline 3 & 0,0766 e $0,0781^{\mathrm{ns}}$ & 0,0766 e $0,0603^{*}$ & 0,0517 e $0,0603^{*}$ \\
\hline 4 & 0,1450 e $0,1187^{*}$ & 0,1450 e $0,1929^{*}$ & 0,1187 e $0,1929^{*}$ \\
\hline 5 & 0,1870 e $0,1437^{*}$ & 0,1870 e $0,2363^{*}$ & 0,1437 e $0,2363^{*}$ \\
\hline 6 & 0,2165 e $0,1635^{*}$ & 0,2165 e $0,2769^{*}$ & 0,1635 e $0,2769^{*}$ \\
\hline
\end{tabular}

* = significativo a $5 \%$ de probabilidade pelo teste $\mathrm{t} ;{ }^{\text {ns }}=$ não significativo a $5 \%$ de probabilidade pelo teste $\mathrm{t}$.

Na Figura 1 se observa o crescimento médio das variáveis dap, altura total e volume total nas três áreas com distintos arranjos espaciais de plantio de eucalipto em sistemas silvipastoris.

b) $-\rightarrow-$ Área $1 \longrightarrow$-Área $2 \ldots \ldots$ Área 3
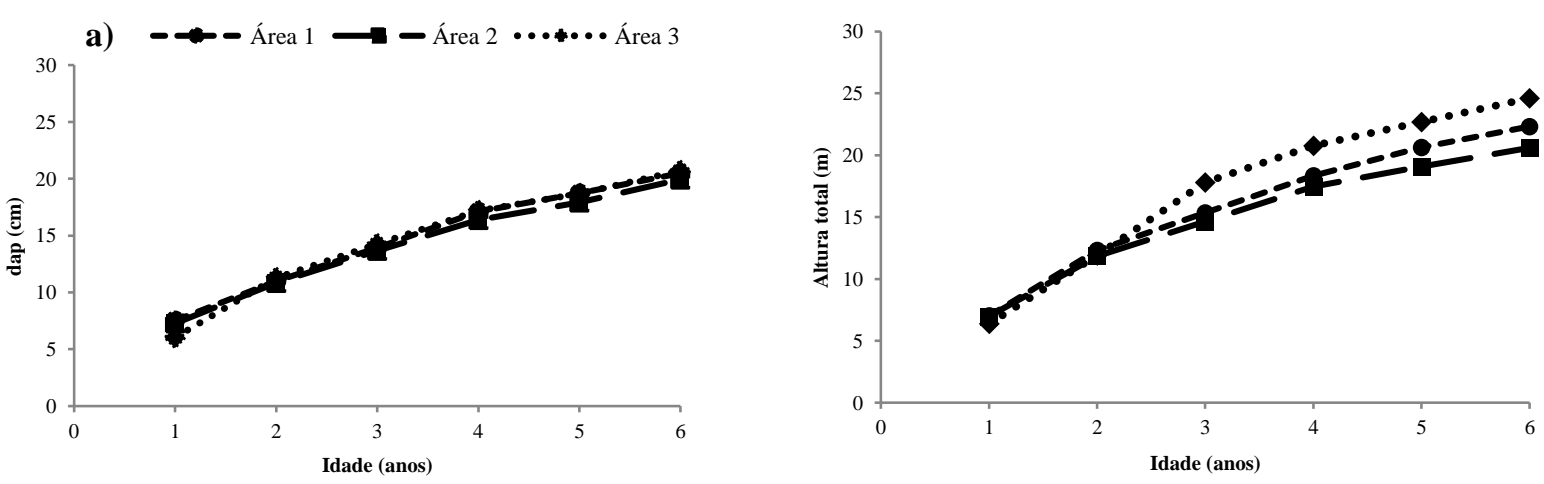

c) - $\rightarrow$ Área $1 \longrightarrow$ - Área 2 ....... Área 3

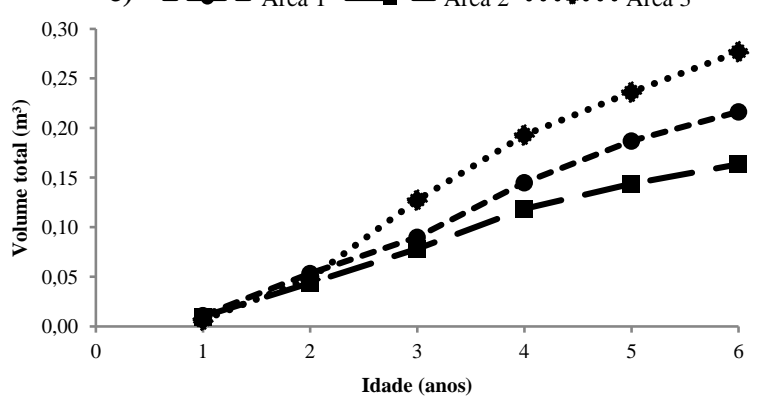

Figura 1. a) Crescimento médio em dap; b) Crescimento médio em altura total; c) Crescimento médio em volume para os diferentes materiais genéticos de eucalipto em sistema silvipastoril nos três arranjos espaciais de plantio no município de Santa Rita do Trivelato - MT. 
As curvas de incremento médio anual (ima) e incremento corrente anual (ica) em volume, ajustadas pela equação de Gompertz em função da
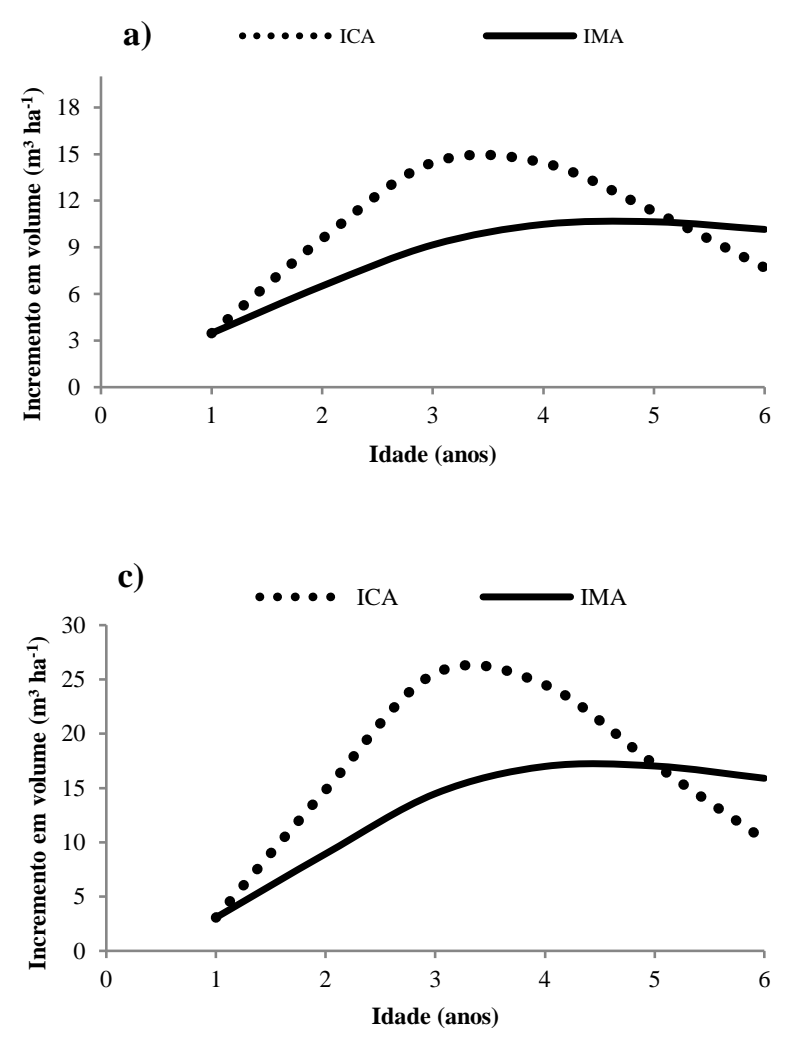

\section{Discussão}

Nos dois primeiros anos de implantação do povoamento não houve diferenças significativas da sobrevivência nos três arranjos avaliados (Tabela 1). A partir do terceiro até o sexto ano de idade, A2 teve a menor sobrevivência, chegando a $62,4 \%$ no sexto ano, que é considerada baixa quando comparada a valores encontrados em outros trabalhos, como de Morais (2006) e Magalhães et al. (2007).

Segundo Melloto et al. (2009), isso pode demonstrar diferentes potenciais de adaptação das espécies ao sítio onde foram implantadas. De acordo com esses autores, diferenças significativas na sobrevivência evidenciam a existência da relação sítio de plantio x espécie, com diferentes respostas da espécie ao local de plantio.

Não houve diferença significativa de sobrevivência entre A1 e A3, sendo de 91,8\% e $92,2 \%$ no sexto ano, respectivamente. Esta porcentagem de sobrevivência observada em A1 e A3 é semelhante a verificada por Ferreira et al. (2014), que avaliaram o crescimento de clone de Eucalyptus urophylla x Eucalyptus grandis em diferentes espaçamentos em Avaré - SP, e observaram a sobrevivência das plantas, aos seis anos de idade, de 93, 97, 95 e $88 \%$, para as unidades idade, para o eucalipto nas três áreas de sistemas silvipastoris, podem ser observadas na Figura 2.

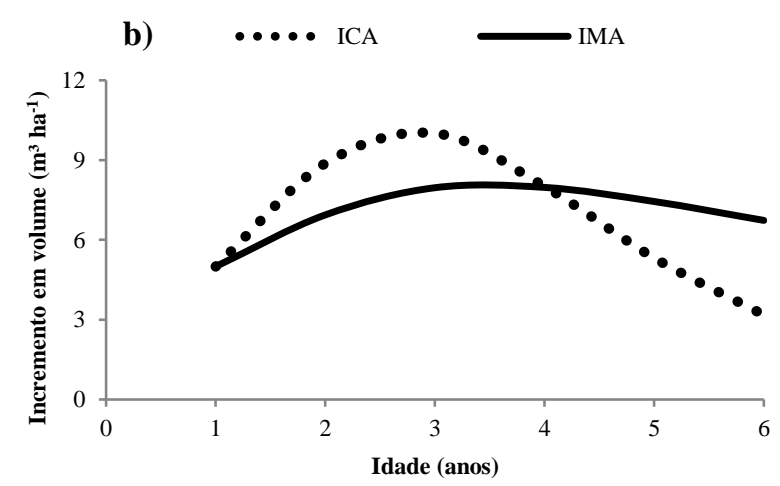

Figura 2. a) Incremento médio anual (ima) e incremento corrente anual (ica) para A1; b) ima e ica para A2; c) ima e ica para A3. experimentais com espaçamento $3 \times 2,5 \mathrm{~m}, 3 \times 2 \mathrm{~m}$, $3 \times 1,5 \mathrm{~m}$ e $3 \times 1 \mathrm{~m}$, respectivamente.

Os valores médios de dap, altura total e volume total das árvores em A1 e A3 aos seis anos de idade (Tabela 2), foram superiores em relação à média de A2. O material de origem clonal exerce superioridade em relação ao material seminal, pois a tendência é que os clones tenham, em função do melhoramento genético, valores maiores de produtividade, sejam em plantios puros ou em sistemas agroflorestais.

Para a variável dap, verificou-se que no primeiro e no sexto ano de idade A1 e A2 não tiveram diferença estatística significativa (Tabela 3). A3 diferiu estatisticamente de A2 apenas no primeiro ano, sendo que do segundo até o sexto ano não teve diferença significativa. Já ao sexto ano de idade não houve diferença estatística entre os daps das árvores das três áreas.

Para a variável altura total (Tabela 3), a maioria das comparações dos valores foi significativa, sendo que no sexto ano de idade A3 apresentou altura média de 24,61 m, seguida de A1 com 22,33 m e de A2 com 20,60 m. A3 obteve altura média no sexto ano superior às alturas encontradas no trabalho de Monte (2009), que avaliou o crescimento de Eucalyptus grandis, tendo 
encontrado aos sete anos e nove meses, altura de 23,7 $\mathrm{m}$ para o tratamento com o primeiro desbaste aos 20 meses e altura de $23,8 \mathrm{~m}$ para o tratamento com o primeiro desbaste aos 28 meses.

Em relação ao volume médio por indivíduo, somente A1 e A2 não apresentaram diferenças significativas aos três anos após o plantio, com produção média de 0,0766 e $0,0781 \mathrm{~m}^{3}$, respectivamente. A3 foi a que obteve o maior volume médio por indivíduo com $0,2769 \mathrm{~m}^{3}$, seguido de $\mathrm{A} 1$ com $0,2165 \mathrm{~m}^{3}$ e de A2 com $0,1635 \mathrm{~m}^{3}$. O volume de A3 foi superior ao volume encontrado $\left(0,25 \mathrm{~m}^{3}\right)$ por Ferreira et al. (2014) para o Eucalyptus urograndis ao sexto ano de idade em espaçamento 3x2 m em Avaré - SP. Segundo Reiner et al. (2011), arranjos maiores permitem maior área útil disponível para cada planta, resultando em maior volume individual.

Quanto ao crescimento médio em dap (Figura 1a), A1, A2 e A3 apresentaram comportamento semelhante. Em relação à altura (Figura 1b) e ao volume de madeira (Figura 1c), A2 obteve o menor crescimento médio, e isso se deve possivelmente à heterogeneidade do plantio, já que se trata de material seminal. A3 foi superior a A1 e A2 no crescimento em altura total e volume. Ferrari et al. (2004), estudando a propagação vegetativa em espécies florestais, apontou vantagens de se utilizar o material de origem clonal em relação ao de origem seminal, pois suas características possibilitam ganhos em produtividade, homogeneidade no plantio, maior qualidade da madeira produzida e resistência a pragas e doenças.

Ao sexto ano de idade A3 apresentou ima de 15,8 $\mathrm{m}^{3} \mathrm{ha}^{-1}$ ano $^{-1}$ (Figura 2c), A1 ima de 10,1 $\mathrm{m}^{3} \mathrm{ha}^{-}$ ${ }^{1}$ ano $^{-1}$ (Figura 2a) e A2 ima de 6,7 $\mathrm{m}^{3} \mathrm{ha}^{-1}$ ano $^{-1}$ (Figura 2b). Em A2 observou-se baixo ima e ica para as plantas seminais em relação a A1 e A3. Além da heterogeneidade dos indivíduos, em A2 o espaçamento mais reduzido entre as plantas nas linhas de plantio pode ter contribuído para antecipar o início da competição, com reflexo negativo no crescimento.

Segundo Campos e Leite (2013), considerando determinado espaçamento inicial em relação à área teórica de competição por parte das raízes entre árvores vizinhas, diferentes arranjos espaciais podem resultar em uma mesma frequência de árvores por hectare. Por exemplo, em arranjos espaciais de $6 \times 1 \mathrm{~m}$ e $3 \times 2 \mathrm{~m}$ a área teórica reservada para cada árvore é a mesma $\left(6 \mathrm{~m}^{2}\right)$, entretanto, o início da competição entre árvores deve ocorrer primeiro no arranjo de 6x $1 \mathrm{~m}$ (menor distância entre os indivíduos da população).

A idade técnica de corte é aquela em que o incremento médio é máximo e nesta idade, este incremento é igual ao incremento corrente anual (Campos e Leite, 2013). O momento de corte para A1 e A3 foi aos cinco anos e para A2 aos quatro anos de idade.

\section{Conclusão}

O material seminal de eucalipto apresentou os menores valores de sobrevivência no sistema silvipastoril, cujo arranjo espacial entre árvores é de $10 \times 2,5 \mathrm{~m}$

O maior crescimento do eucalipto foi observado nos arranjos espaciais de 10x3 m e $3 \times 4 \times 16 \mathrm{~m}$ para os clones H13 e $\mathrm{IO} 42$ respectivamente, aos seis anos de idade.

\section{Referências}

Alvares CA, Stape JL, Sentelhas PC, Gonçalves JLM, Sparovek G (2013) Köppen's climate classification map for Brazil. Meteorologische Zeitschrift, Stuttgart, v.22, n.6, p.711-728.

Andrade CMS (2000) Estudo de um sistema agrissilvipastoril, constituído por Eucalyptus urophylla S.T. Blake e Panicum maximum Jacq. cv. Tanzânia-1, na região dos Cerrados de Minas Gerais, Brasil. Viçosa: UFV. 102p. Dissertação (Mestrado em Zootecnia).

Andrade CMS de, Salman AKD, Oliveira, TK de (2012) Guia arbopasto: manual de identificação e seleção de espécies arbóreas para sistemas silvipastoris. Brasília: Embrapa, 345p.

Aquino AM, Assis RL (2005) Agroecologia: Princípios e Técnicas para uma Agricultura Orgânica Sustentável. 1 ed. Embrapa, 517p.

Barros DA, Machado AS, Acerbi Júnior FW, Scolforo JRS (2002) Comportamento de modelos hipsométricos tradicionais e genéricos para plantações de Pinus oocarpa em diferentes tratamentos. Boletim de Pesquisa Florestal, Colombo, n.45, jul./dez. 28p.

Campos JCC, Leite HG (2013) Mensuração florestal: perguntas e respostas. 4. ed. Viçosa: UFV. $605 p$.

Couto L, Roath RL, Betters DR, Garcia R, Almeida CC (1994) Cattle and sheep in eucalypt plantations: a silvopastoral alternative in Minas Gerais. Agroforestry Systems, v.28, n.2, p.173-184.

Cruz PTD (2007) Viabilidade técnica e econômica de sistemas silvipastoris com Eucalyptus spp. na região Noroeste do Estado do Paraná. Maringá: UEM. 92p. Dissertação (Mestrado em Agronomia).

Ferrari MP, Grossi F, Wendling I (2004) Propagação vegetativa de espécies florestais. Embrapa Floresta. Documentos, 94, Colombo-PR. 22p.

Ferreira DHAA, Leles PSS, Machado EC, Abreu AHM, Abílio FM (2014) Crescimento de clone de 
Eucalyptus urophylla $x$ E. grandis em diferentes espaçamentos. Floresta, v.44, n.3, p.431-440, jul./set.

IBÁ - Indústria Brasileira de Árvores (2019). Relatório 2018. Disponível em: < https://iba.org/datafiles/publicacoes/relatorios/ibarelatorioanual2019.pdf >. Acesso em: 11 nov/2019.

Magalhães WM, Macedo RLG, Venturin N, Higashikawa EM, Júnior MY (2007) Desempenho silvicultural de clones e espécies/procedências de Eucalyptus na região noroeste de Minas Gerais. Cerne, v.13, n.4, p.368-375, out./dez.

Melotto A, Nicodemo ML, Bocchese RA, Laura VA, Miguel Neto MG, Schleder DD, Pott A, Silva VP (2009) Sobrevivência e crescimento inicial em campo de espécies florestais nativas do Brasil central indicadas para sistemas silvipastoris. Revista Árvore, v.33, n.3, p.425-432.

Monte MA, Reis MGF, Reis GG, Leite HG, Cacau FV, Alves FF (2009) Crescimento de um clone de eucalipto submetido a desrama e desbaste. Revista Árvore, v.33, n.5, p.777-787.

Morais VM (2006) Dinâmica de crescimento de eucalipto clonal sob diferentes espaçamentos na região noroeste do Estado de Minas Gerais. Lavras: UFLA. 63p. Dissertação (Mestrado em Engenharia Florestal).

Porfírio-da-Silva V (2012) Produtividade em sistema de integração lavoura-pecuária-floresta no subtrópico brasileiro. Curitiba: UFPR. 110p. Tese (Doutorado em Agronomia).

Reiner DA, Silveira ER, Szabo MS (2011) O uso do eucalipto em diferentes espaçamentos como alternativa de renda e suprimento da pequena propriedade na região sudoeste do Paraná. Synergismus scyentifica, v.6, n.1, p.10-18.

Toledo REB, Alves PLCA, Valle CF, Alvarenga SF (1999) Manejo de Brachiaria decumbens e seu reflexo no desenvolvimento de Eucalyptus grandis. Scientia Forestalis, n.55, p.129-141, jun. 